\title{
Accountability in the City of Toronto's 10 Long-Term Care Homes
}

\section{Lobligation de rendre compte dans les 10 foyers de soins de longue durée de la cité de Toronto}

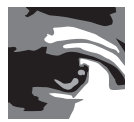 \\ LINDSAY WYERS, MHS(C) \\ Master of Health Science Candidate, Faculty of Health Sciences \\ University of Ontario Institute of Technology \\ Oshawa, ON \\ BRENDA GAMBLE, PHD \\ Associate Professor, Faculty of Health Sciences \\ University of Ontario Institute of Technology \\ Oshawa, ON \\ RAISA B. DEBER, PHD \\ Professor, Institute of Health Policy, Management E Evaluation \\ University of Toronto \\ Toronto, ON
}

\begin{abstract}
Long-term care (LTC) residential homes provide a supportive environment for residents requiring nursing care and assistance with daily living activities. The LTC sector is highly regulated. We examine the approaches taken to ensure the delivery of quality and safe care in 10 LTC homes owned and operated by the City of Toronto, Ontario, focusing on mandatory accountability agreements with the Local Health Integration Networks (LHINs). Results are based on document review and seven interviews with LTC managers responsible for the management and operation of the 10 LTC homes. One issue identified was the challenges associated with implementing new legislative and regulatory requirements to multiple bodies with differing requirements, particularly when boundaries do not coincide (e.g., the City of Toronto's Long-Term Care Homes and Services Division must establish 10 different accountability agreements with the five LHINs that span into the City of Toronto's geographic area).
\end{abstract}




\section{Résumé}

Les foyers de soins de longue durée (SLD) offrent un ensemble de soutien aux résidents qui nécessitent des services infirmiers et de l'aide pour mener à bien leurs activités quotidiennes. Le secteur des SLD est très réglementé. Nous examinons les démarches prises pour assurer la prestation de soins sécuritaires de qualité dans 10 foyers de SLD administrés par la cité de Toronto, en Ontario, en mettant l'accent sur les ententes d'obligation redditionnelle conclues avec les réseaux locaux d'intégration des services de santé (RLISS). Les résultats se fondent sur une revue de la documentation et sur sept entrevues menées auprès de gestionnaires responsable de la gestion et de lexploitation dans les 10 foyers de SLD. Un des enjeux repérés a trait aux défis liés à la mise en ouvre des exigences légales et réglementaires dans plusieurs organismes dont les besoins diffèrent, particulièrement quand les territoires ne coïncident pas (par exemple, la Division pour les services et foyers de soins de longue durée de la cité de Toronto doit conclure 10 ententes quant à l'obligation de rendre compte, et ce, avec les cinq RLISS qui couvrent l'aire géographique de la ville).

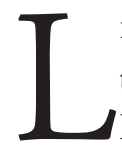

ike other countries, Canada's population is aging. By 2026, it is estimated that one in five Canadians will have reached the age of 65 years (Health Canada and Interdepartmental Committee on Aging and Seniors Issues 2002). Supporting this aging population will require efforts directed at implementing strategies for healthy aging. This includes the provision of supportive environments within communities for seniors and sustainable government programs (Health Canada and Interdepartmental Committee on Aging and Seniors Issues 2002).

Residential long-term care (LTC) homes provide a supportive environment and 24-hour nursing care for the small but vulnerable proportion of seniors and other individuals who are unable to live on their own due to cognitive/physical impairment, challenges with daily living activities and/or the lack of informal support. Although the number of LTC beds across Canada per 1,000 seniors has remained stable, the level of care has become more intense due to more complex conditions and health needs. Overall, the majority of residents in LTC homes in Canada are female, single, over the age of 85 years old, and cognitively impaired (CIHI 2011).

The provision of safe, quality and efficient residential LTC for this vulnerable population is a high priority for residents, families, governments and providers. LTC homes are not required to be a publicly insured service under the terms of the Canada Health Act (Madore 2005). Nonetheless, most jurisdictions cover a proportion of the costs for certain populations (Berta et al. 2006). A number of different funding models exist that rely on a mix of public (e.g., provincial/territorial and municipal governments) and private (e.g., private insurance, co-payments paid by residents) sources. Variation also exists across Canada in terms of ownership status of the homes (Berta et al. 2006). Although there are many unregulated LTC 
homes (often called "retirement homes"), the formal LTC sector in Ontario is highly regulated and must respond to a variety of legislative/regulatory measures and policy decisions made by different levels of government.

Currently in Ontario, there are approximately 77,605 residents in 628 regulated LTC homes (Ontario Association of Non-Profit Homes and Services for Seniors 2013). Recent media reports have foregrounded the need to address abuse and neglect in Ontario's LTC home sector. The Long-Term Care Task Force on Resident Care and Safety in Ontario was established in 2011 in response to these reports highlighting the need to recognize the rights of residents to receive quality care in a safe, respectful environment free of abuse; it has issued progress reports (Long-Term Care Task Force on Resident Care and Safety 2013). Providing quality and safe care for LTC residents is also a high priority for Ontario's Ministry of Health and Long-Term Care (MOHLTC). In a January 2013 press release, the Minister of the MOHLTC stated: "My ministry has been working closely with task force members, and I am proud of the actions and recent investments the ministry has made to further support longterm care homes, and staff to improve the care and safety of residents" (http://www.newswire. $\mathrm{ca} / \mathrm{en} / \mathrm{story} / 1106837 /$ working-together-to-provide-safe-care-to-residents-in-long-term-care).

\section{Purpose}

Ontario's LTC homes can be categorized into three sub-sectors, based on their public-private ownership status: private not-for-profit (e.g., religious or lay groups), private for-profit (e.g., individual, private organizations or corporations) and public (e.g., City of Toronto's LTC homes) (Berta et al. 2006). This study focuses on the 10 public LTC homes owned by the City of Toronto, Ontario; a companion paper in this volume deals with other private LTC homes in Ontario (Berta et al. 2014). Responsibility for both the operation and management of these 10 homes rests with the City of Toronto's Long-Term Care Homes and Services Division (the Division). The Division is responsible for providing a variety of long-term healthcare services in the City of Toronto. A number of different factors influence the quality and care delivered to residents, including management structure and process (Wodchis et al. 2014). The Division's mission statement is to "... provide a continuum of high quality longterm care services to eligible adults in both long-term care homes and the community." The Division is guided by a set of core values: Compassion, Accountability, Respect and Excellence (CARE). The CARE values are intended to be shared by all stakeholders, drive culture and priorities and provide a framework in which all decisions are based. A general manager, three directors and 10 administrators, along with a number of other senior staff, provide overall leadership to the Division using a participatory style of management that involves shared decision-making and shared responsibility for the Division's performance.

\section{City of Toronto's 10 LTC Homes}

Each of the 10 LTC homes has an administrator whose primary focus is on the operations of that particular home. A variety of healthcare, social care and administrative staff provide "nurs- 
ing and personal care, medical, recreational, rehabilitation, nutritional, spiritual, social work, housekeeping, laundry and administrative services." Volunteers also play an important role providing assistance, visitations, programs and activities for the residents.

The City's LTC homes have 2,641 approved beds (17.3\% of the regulated LTC beds in Toronto) and provide permanent, convalescent and short-stay accommodations to a diverse population (mainly seniors) from more than 50 countries of origin and speaking 38 languages. The Division's decision-making framework for providing support and activities for the 10 LTC homes takes into account the cultural, religious and sexual diversity of their residents, as well as diverse abilities such as the level of cognitive ability. The majority of permanent residents have some form of cognitive impairment and require nursing care and assistance with daily living activities.

In 2006, the Ontario government implemented the regionalization of healthcare services with the introduction of 14 Local Health Integration Networks (LHINs). Each LHIN is responsible for the planning, integration and funding of specified health services in its region, including hospitals and community care, as well as LTC services. To ensure the responsible use of healthcare resources, accountability agreements between healthcare providers and LHINs and between LHINs and government have been established. The LHIN boundaries are not necessarily co-terminus with those of the local government. Toronto falls into five different LHINs, some of which also encompass areas outside the city boundaries. Accordingly, the 10 public LTC homes operated by the Division are situated in five different LHINs, and this has resulted in the establishment of 10 different accountability agreements with five different LHINs. We examine the approaches taken to ensure the delivery of quality and safe care in LTC homes owned by the City of Toronto by focusing on the challenges and/or benefits resulting from these accountability agreements.

\section{Methodology}

Data collection for this case study used data triangulation from more than one type of data source to give more insight into the sub-sector and to identify more easily any inconsistencies found between the data (Bickman and Rog 1998). We used a combination of document review and in-depth interviews with seven LTC managers from the City of Toronto's LongTerm Care Homes and Services Division who are responsible for implementing the accountability requirements within this sub-sector. Participants were each given a unique identifier, e.g., M1, M2, etc. Participants provided informed consent prior to data collection, and the Research Ethics Boards at University of Ontario Institute of Technology and the City of Toronto Long-Term Care Homes and Services Division provided ethics approval. One-hour semi-structured interviews were conducted via telephone or in person.

Documents reviewed included peer-reviewed literature, grey literature (e.g., professional association websites) and provincial legislation and regulations. The City of Toronto Long-Term Care Homes and Services Division provided strategic directions documents, report cards, efficiency review documents, annual reports and long-term care home service 
accountability agreements (L-SAAs). Following identification of the relevant documents, each was summarized and reviewed by at least two members of the research team (which included at least one expert from the LTC sub-sector) to ensure consensus. Similar procedures were used for the coding of the key informant interviews to validate the themes identified.

\section{Results}

\section{Approaches to Accountability}

In terms of "to whom," our respondents noted multiple layers. They noted that providing quality and safe care to the residents was the first and most important priority and that they believed that the Division was accordingly primarily:

... accountable to the residents and their families, who in some cases provide a copayment for their accommodations .... and by extension we are accountable to the local citizens. (M1)

However, management is not only accountable to the residents and their families but also to other stakeholders. As articulated by one respondent:

The Division receives funding and therefore is financially accountable to the Province of Ontario, Central East LHIN, Toronto Central LHIN, Central LHIN, Central West LHIN and Mississauga/Halton LHIN and the City of Toronto Council. (M2)

While respondents agreed, "there are many layers" (M3) of accountability, they agreed that primary governance and oversight lies with Toronto's City Council:

even though the majority of the funding is from the province, they [City Council] have governance over the operations. (M1)

In terms of how, accountability in this sub-sector uses a combination of all four mechanisms of accountability (financial incentives, regulation, information directed to potential users and reliance on professionalism) identified in the conceptual framework (Deber 2014). These do not entirely derive from the government. For example, the Long-Term Care Task Force on Resident Care and Safety in Ontario released an 18-item action plan in 2012 to improve safety in Ontario's LTC homes (Long-Term Care Task Force Ontario 2012). A subsequent report provided educational/training strategies for staff (i.e., professionalism) and support tools for staff and families (i.e., information directed to potential users), as well as earmarking resources (i.e., financial incentives) for the recruitment of qualified clinical, support and administrative staff (Long-Term Care Task Force on Resident Care and Safety 2013). 


\section{Role of Regulation}

Regulation plays a significant role in ensuring accountability in the LTC home sector in Ontario. In the opinion of one respondent: "After nuclear power plants, long-term care homes are the most regulated sector. (M4)"

In respect to whether the Division or LTC homes have any influence over these regulations, one respondent commented:

We have an opportunity to influence policy ... or influence the direction of various legislation or regulations, and certainly provide evidence to the direction in which change needs to be made. (M1)

All regulated LTC homes in Ontario are licensed and approved by the MOHLTC. Regardless of the ownership status (private not-for-profit, private for-profit and public), LTC homes are governed by the Long-Term Care Homes Act (LTCH) of 2007 and Ontario Regulation 79/10 (Legislative Assembly of Ontario 2007). In addition, a variety of other legislation and regulations apply to this sector, as noted by two respondents from the senior management team:

They [regulations] are all specified from the Ministry standpoint, long-term care home acts, including homemakers and nurses' services, health and safety, privacy (MFIPPA [the Municipal Freedom of Information and Protection of Privacy Act] and PHIPA [the Personal Health Information Protection Act]), and so many others ... even the AODA ... the fire code, lots [of others] as well. (M5)

The Act ... public health requirements, Ministry of Labour, Health Quality Ontario ... there are many, many layers. (M6)

The LTCH Act and Regulation 79/10 are considered the foundation of the Ontario government's commitment to reforming the accountability of LTC homes. LTC homes are accountable for providing safe, respectful, quality health and social care services, as well as safeguarding residents' rights. The Long-Term Care Homes' Quality Inspection Program was initiated to ensure that LTC homes comply with legislation and regulations. Health Quality Ontario (HQO) makes the data available to the public on the Ontario MOHLTC website.

Accreditation processes are overseen by Accreditation Canada or the Commission on Accreditation of Rehabilitation Facilities and are encouraged by MOHLTC through financial incentives to accredited LTC homes. Two of the LHINs to which the Division must report (Central East and Central West LHINs where three LTC homes are located) go beyond this and require accreditation by a recognized Canadian accreditation program as a performance requirement. In 2012, the City of Toronto's Long-Term Care Homes and Services was awarded 
Accreditation with Exemplary Standing by Accreditation Canada, their highest level of performance recognition in meeting the requirements of the Qmentum accreditation program (Mitchell et al. 2014).

\section{Long-Term Care Home Service Accountability Agreements}

With the enactment of the Local Health System Integration Act (LHSIA) in 2006, the LHINs began the negotiation of service accountability agreements (SAAs) between the LHINs and health service providers (HSPs) funded by the LHINs in accordance with the timetable set out in LHSIA, O.Reg. 279. LHINs were originally expected to enter into SAAs with LTC homes by March 31, 2010; however, the L-SAA was developed within the context of the LTCH Act. The L-SAAs are for a period of three years. Accordingly, LTC homes signed their first L-SAA on July 1, 2010, concomitant with the date of proclamation of the LTCH Act, and were effective until March 31, 2013.

The LHINs have an accountability framework that supports their legislative requirements with respect to the LTC sector, but this framework acts only as a guideline. The planning and accountability cycle within the LHIN and HSPs began in the fall of the final year of the agreement. The beginning of this cycle is the Long-Term Care Home Accountability Planning Submission (LAPS). The LAPS informs discussion with the LHIN in regards to the L-SAA. It provides a tool for homes to describe their services, and is composed of two parts: (a) an overview of the LTC home that includes general identifying information, bed types and numbers offered within the home, structural classification and listing of additional services provided to residents; and (b) the Service Plan narrative, which will allow the LTC home to provide information that describes services that the home operates or plans to operate within each year of the agreement. There are strict instructions on how this is to be completed. The LAPS documents facilitate discussions with the LHIN and become appendices to the L-SAA.

Commenting on the accountability process and who had final say on the contents of the L-SAA, one respondent indicated:

We had input and some opportunity with respect to the development of service accountability agreements, but they are accountability agreements and not contracts, so you don't necessarily negotiate them, you discuss, you provide feedback but in the end they [LHIN] can prescribe, and in some respects it had been prescribed. (M3)

There was consensus from the respondents that there was oversight provided from the Division at the provincial L-SAA Steering Committee (in the formulation of the agreements).

While there is guidance from the provincial steering committee to align the processes and to provide guidance to the LHINs, each LHIN ultimately has flexibility on how it carries out the L-SAA process. One result is that timelines may vary for each LHIN, and not be consist- 
ent with the Division approval process. One requirement of the LAPS and L-SAA is having the submission and agreement endorsed by the governing body and executed by two signing authorities that can bind the organizations. For the Division, this means having City Council approval, which requires time for management to review and obtain the necessary approvals, and often this process does not coincide with the LHINs' timelines.

\section{Performance Indicators}

Another portion of the L-SAA agreement that varies by LHIN is the performance indicators used to measure the HSP' performance and tools used for demonstrating accountability. The L-SAA Indicators Working Group is responsible for developing recommendations for consideration by the L-SAA Steering Committee regarding L-SAA performance indicators. The Working Group is composed of LTC sector representatives, MOHLTC, HQO and LHIN staff, and is chaired by an LHIN Senior Director of the Health System Indicator Initiative Steering Committee. For the 2013-2016 L-SAA, the working group created the following sets of indicators to reflect the Pan-LHIN "Ontario" systems imperative: Enhancing Coordination and Transitions of Care; Maintaining Achievements in Access, Accountability and Safety; and Ensuring Sustainable Organizational Health. Within these categories, there were four indicators that were in every L-SAA. Each indicator has a performance target, performance corridor and a performance standard. Because the Division has LTC homes situated in five different LHINs, it must thus comply with five different processes. This has implications for the Division's financial and human resources. Even within one LHIN, there are differences for performance targets for the same indicator across different sub-sectors.

In addition to the four Pan-LHIN indicators, the Division reports on 17 separate performance indicators that were identified by the five different LHINs. Reporting on all the indicators requires resources and systems in place in order to meet the reporting requirements laid out in the L-SAA. One respondent commented that while reporting on the indicators is achievable, it was time-consuming:

It's not difficult for us to achieve them [indicators], it is difficult for us when we are reporting to the five LHINs ... the five LHINs don't even use the same template, for their reporting systems ... we find the workload really difficult. (M2)

Concern was also raised regarding the ability to get the work done in a timely manner:

....it is not that the work doesn't get done, it doesn't get done in a timely fashion

because of the different reporting systems that we need to meet. (M3)

\section{Resourcing Accountability}

Whether an increase in regulation, accountability requirements or performance indicators, in most instances, respondents said that meeting their accountability requirements was getting 
increasingly challenging. The proportion of funding was decreasing, while the expectations and requirements were increasing. Our respondents believed that insufficient funding was provided to implement new legislative and regulatory requirements. For example, although the Division attempts to be sensitive to the cultural needs of their residents and their families, including incorporating ongoing review and revision of policies, prioritizing could be affected by legal requirements. One respondent expressed frustration with the lack of additional funds to meet the requirements of the Accessibility for Ontarians with Disabilities Act:

... one of the residents was demanding an interpreter; this is a very expensive proposition to have an interpreter available constantly for an individual resident, but there is an act that requires that you do so. (M2)

Quality is a major concern for the Division, especially when cuts are made to an already limited budget. One respondent commented on the struggles on being a municipal home:

... you are limited on how far back you can cut without having an adverse effect on your residents, while still providing quality of care. (M7)

As noted previously, the Toronto City Council provides funds to and oversight of the Division. Recognizing that the Division is one of the many responsibilities of the City Council, delivering care in an efficient matter is an important part of the Division's accountability to the City of Toronto:

we [the Division] subject ourselves to higher levels of accountability, so there is the value for money. (M1)

\section{Discussion and Conclusion}

Our respondents stressed that delivering quality and safe care to the residents of the City of Toronto's 10 LTC homes is a top priority. Demonstrating accountability to funders is also required to ensure the 10 LTC homes have the resources needed to deliver care to this vulnerable population. The necessity of establishing 10 different accountability agreements with five different LHINs for its 10 LTC homes has brought to the foreground implementation challenges in terms of both time and human resources for the Division. Each LHIN is given some latitude to define performance indicators to better respond to the needs of the population that it serves. As a result, each home has autonomy and the potential to negotiate performance indicators that are meaningful to the home (Ontario Local Health Integration Network 2012). As well, there are different funding opportunities for each home depending on what LHIN it resides in, including behavioural support units and process improvement initiatives (e.g., through the Health System Improvement Pre-Proposal). Although this can present 
difficulties in responding to the various requirements, the ability to respond to local health needs is seen as one of the benefits of regionalization. Considering the diversity between the 10 LTC homes, accountability agreements with the different LHINs strengthen each home's ability to meet the needs of its clients.

Funding for the 10 LTC homes is transferred from the LHINs to each individual LTC home, and funding may vary depending on LHIN-funded priorities; however, the Toronto City Council allocates funds to the Division based on a global budget. This adds another layer of complexity that can potentially lead to resource planning challenges. For example, Toronto's City Council implemented a 10\% funding cut in 2011, which affected all Divisions, including the Long-Term Care Homes and Services Division.

Results of this study have brought to the foreground the challenges service providers face when implementing new legislative and regulatory requirements. This is increasingly challenging when negotiating accountability agreements with multiple organizations (in this case, LHINs) that can use funding tools to force compliance. This experience is not unique to Toronto's Long-Term Care Homes and Services Division (which deliver not only residential care but also community services and supportive housing services), but is also experienced by community agencies that receive public funding and provide services to specific populations located in different LHINs. Accountability through performance indicators can be highly measurable. However, the implementation of measures to demonstrate quality and value for money must take into consideration the governance structure of service providers and the relationship between the funders and providers.

As in other healthcare sectors and within the LTC sector, providers are not only responsible to the recipients of care (in this case, residents and their families) but also to other stakeholders who provide funding and are responsible for ensuring regulatory requirements are met to demonstrate accountability. The creation and implementation of accountability agreements in the City of Toronto's 10 LTC homes requires flexibility to accommodate and respond to the needs of the residents and their families, as well as the budget requirements of the City of Toronto. This does not come without its challenges for the Division responsible for the operation of the LTC homes. However, the Division recognizes these challenges and endeavours to ensure the regulatory structures are adhered to while maintaining balanced budgets, but more importantly ensuring quality and safe care for their residents.

\section{Acknowledgements}

This study was funded by CIHR-PHSI Grant (CIHR Grant Number PHE-101967).

Correspondence may be directed to: Brenda Gamble, PhD, Associate Professor, Faculty of Health Sciences, University of Ontario Institute of Technology, 2000 Simcoe St. North, Oshawa, ON L1H 7K4; e-mail:brenda.gamble@uoit.ca. 


\section{Accountability in the City of Toronto's 10 Long-Term Care Homes}

\section{References}

Berta, W., A. Laporte and W. P. Wodchis. 2014. "Approaches to Accountability in Long-Term Care." Healthcare Policy 10(Special Issue): 132-144.

Berta, W., A. Laporte, D. Zarnett, V. Valdmanis and G. Anderson. 2006. “A Pan-Canadian Perspective on Institutional Long-Term Care." Health Policy 79(2-3): 175-94.

Bickman, L. and D.J. Rog, eds. 1998. Handbook of Applied Social Research Methods. Thousand Oaks, CA: Sage Publications.

Canadian Institute for Health Information. 2011. Health Care in Canada 2011: A Focus on Seniors and Aging. Ottawa, ON. Retrieved March 15, 2014. <https://secure.cihi.ca/estore/productFamily. htm?locale $=$ en $\& \mathrm{pf}=\mathrm{PFC} 1677>$.

Deber, R.B. 2014."Thinking about Accountability." Healthcare Policy 10(Special Issue): 12-24.

Health Canada and Interdepartmental Committee on Aging and Seniors Issues. 2002. Canada's Aging Population. Ottawa, ON: Health Canada. Retrieved March 15, 2014. <http://publications.gc.ca/collections/Collection/H39608-2002E.pdf>.

Legislative Assembly of Ontario. 2007. Bill 140: An Act Respecting Long-Term Care Homes. Legislation. Retrieved March 15, 2014. <http://www.e-laws.gov.on.ca/html/source/statutes/english/2007/elaws_src_s07008_e.htm>.

Long-Term Care Task Force Ontario. 2012. Long-Term Care Task Force on Resident Care and Safety. Retrieved March 15, 2014. <http://longtermcaretaskforce.ca/>.

Long-Term Care Task Force on Resident Care and Safety. 2013. Progress Report: Delivering on the Action Plan to Address Abuse and Neglect in Long-Term Care Homes. Retrieved March 15, 2014. < http://longtermcaretaskforce. $\mathrm{ca} /$ images/uploads/LTCFTReportEnglish.pdf>.

Madore, O. 2005. The Canada Health Act: Overview and Options. Ottawa, ON: Library of Parliament. Retrieved March 15, 2014. <http://www.parl.gc.ca/Content/LOP/ResearchPublications/944-e.htm>.

Mitchell, J.I., W. Nicklin and B. MacDonald. 2014. “The Accreditation Canada Program: A Complementary Tool to Promote Accountability in Canadian Healthcare." Healthcare Policy 10(Special Issue): 150-53.

Ontario Association of Non-Profit Homes and Services for Seniors. 2013. Long Term Care Provincial Snapshot. Woodbridge, ON: OANHSS. Retrieved March 15, 2014. <http://ocsco.ca/uploads/Image/OANHSS_ Provincial_Snapshot.pdf>.

Ontario Local Health Integration Network. 2012. Long-Term Care Home Accountability Planning Submission (Laps). Toronto, ON: Ontario Local Health Integration Network. Retrieved March 15, 2014. <http://www.torontocentrallhin.on.ca/page.aspx?id=2708" http://www.torontocentrallhin.on.ca/page.aspx?id=2708>.

Wodchis, W.P., T. Burns, B. Chan, W. Berta, K. McGilton, K. Walker et al. 2014. Determinants of Quality in Ontario Ltc Homes (2011-2014). Retrieved March 15, 2014. < http://www.ihpme.utoronto.ca/about/research/ hsr/projects/ltc $>$. 